\title{
Cord blood vitamin D and the risk of acute lower respiratory infection in Indigenous infants in the Northern Territory
}

$\mathrm{O}$ ne fifth of Indigenous infants born in the Northern Territory are hospitalised with an acute lower respiratory infection (ALRI) during their first year of life. ${ }^{1}$ Several international studies have reported an inverse relationship between cord blood vitamin D levels and infant respiratory infections. ${ }^{2-4}$ As exposure to sunshine is the most important influence on vitamin D status, there has been little consideration of the relationship between vitamin D status and disease in the tropical north of Australia.

Vitamin D is produced in the skin after exposure to sunlight. Subsequent hydroxylation in the liver yields the dominant circulating vitamin D metabolite, $25(\mathrm{OH}) \mathrm{D}_{3}$. The discovery that vitamin $\mathrm{D}$ receptors are widely distributed throughout human tissues and that several cell types, including those of the immune system, can synthesise the active vitamin D metabolite $\left(1,25(\mathrm{OH})_{2} \mathrm{D}\right)$ from $25(\mathrm{OH}) \mathrm{D}_{3}$ has prompted renewed interest in the role of vitamin D. Vitamin D is required for innate (antimicrobial peptide production) and adaptive (favours response by $\mathrm{T}_{\mathrm{h}} 2$ effector $\mathrm{T}$ cells) immune responses. ${ }^{5}$ These may be particularly important in the respiratory tract of the developing infant, and perhaps relevant to the relationship between cord blood vitamin D levels and the risk of respiratory infection..$^{2-4}$

Anne B Chan MB BD, FRACP, PhD

Ross M Andrews PhD, MPH, MAppEpid

1 Menzies School of Health Research, Darwin, NT.

2 Menzies School of Health Research,

Brisbane, QLD.

michael.binks@ menzies.edu.au

doi: 10.5694/mja15.00798

\section{Abstract}

Objectives: To assess vitamin D status in Indigenous mothers and infants in the Northern Territory, and to determine whether cord blood vitamin D levels are correlated with the risk of infant hospitalisation for acute lower respiratory infection (ALRI).

Design and participants: Within a nested cohort of 109 Indigenous mother-infant pairs recruited between 2006 and 2011, we used liquid chromatography-mass spectrometry to measure vitamin $\mathrm{D}\left(25(\mathrm{OH}) \mathrm{D}_{3}\right)$ levels in maternal blood during pregnancy $(n=33$; median gestation, 32 weeks [range, 28-36 weeks]) and at birth ( $n=106$; median gestation, 39 weeks [range, 34-41 weeks]), in cord blood ( $n=84$; median gestation, 39 weeks [range, 36-41 weeks]), and in infant blood at age 7 months ( $n=37$; median age, 7.1 months [range, 6.6-8.1 months]).

Main outcome measure: ALRI hospitalisations during the first 12 months of infancy, identified using International Classification of Diseases coding (J09-J22, A37-A37.9).

Results: Compared with mean $25(\mathrm{OH}) \mathrm{D}_{3}$ levels in maternal blood during pregnancy $(104 \mathrm{nmol} / \mathrm{L})$, mean levels were $23 \%$ lower in maternal blood at birth $(80 \mathrm{nmol} / \mathrm{L})$ and $48 \%$ lower in cord blood samples $(54 \mathrm{nmol} / \mathrm{L})$. The mean cord blood $25(\mathrm{OH}) \mathrm{D}_{3}$ concentration in seven infants subsequently hospitalised for an ALRI was $37 \mathrm{nmol} / \mathrm{L}(95 \% \mathrm{Cl}$, $25-48 \mathrm{nmol} / \mathrm{L})$, lower than the $56 \mathrm{nmol} / \mathrm{L}(95 \% \mathrm{Cl}, 51-61 \mathrm{nmol} / \mathrm{L})$ in the 77 infants who were not hospitalised with an ALRI $(P=0.025)$.

Conclusions: Cord blood $25(\mathrm{OH}) \mathrm{D}_{3}$ concentrations were about half those in maternal blood during the third trimester of pregnancy (about 7 weeks earlier). Most cord blood levels (80\%) were classified as vitamin D insufficient $(<75 \mathrm{nmol} / \mathrm{L}$ ) by existing guidelines, and were lower among infants who were subsequently hospitalised with an ALRI.

Neonates and breastfed infants rely almost exclusively on maternal vitamin D. ${ }^{8,9}$ According to national population surveys, the prevalence of low 25(OH)D levels $(<50 \mathrm{nmol} / \mathrm{L})$ in women during pregnancy varies from $10 \%$ among women in southeast Queensland ${ }^{10}$ to more than $80 \%$ in dark-skinned and/or veiled women in Melbourne, Victoria. ${ }^{11}$ In Far North Queensland, a small study of pregnant women at mid-gestation (93 non-Indigenous and 23 Indigenous women) found that only eight $(7 \%)$ had $25(\mathrm{OH}) \mathrm{D}$ values under $75 \mathrm{nmol} / \mathrm{L}^{12}$ While little is known about the vitamin D status of pregnant Indigenous women and children, dark skin is a risk factor for low vitamin D levels, ${ }^{7}$ and our recently published data indicate that about $40 \%$ of hospitalised Indigenous infants in the NT (median age,
7 months) had $25(\mathrm{OH}) \mathrm{D}_{3}$ levels below $75 \mathrm{nmol} / \mathrm{L}^{13}$

The aims of our study were to describe the natural history of vitamin D status from the third trimester of pregnancy to infancy (age 7 months), and to determine whether low vitamin $\mathrm{D}$ levels at birth (cord blood $\left.25(\mathrm{OH}) \mathrm{D}_{3}\right)$ were associated with an increased risk of ALRI hospitalisation during the first year of life.

\section{Methods}

\section{Participants and study design}

From our randomised controlled trial of maternal pneumococcal vaccination (PneuMum; ClinicalTrials.gov NCT00714064), we established a cohort of 109 Indigenous motherinfant pairs from the Top End of the 
Northern Territory, in regions serviced exclusively by Royal Darwin Hospital. Participants were recruited from 2006 to 2011, and followed over several visits from the third trimester of pregnancy until the infant was 7 months old. Within this cohort, blood was available from 33 mothers during the third trimester of pregnancy (<36 weeks), from 106 mothers at birth, from 84 cord specimens ( $<72$ hours after birth), and from 37 infants at age 7 months. Vitamin D levels were measured in each of these blood samples to assess temporal trends in vitamin D status during the birth period, and to establish the exposure of interest (cord blood vitamin D status) before ascertaining the primary outcome, ALRI hospitalisation before 12 months of age.

\section{Vitamin D measurements}

Serum $25(\mathrm{OH}) \mathrm{D}_{3}$ and $25(\mathrm{OH}) \mathrm{D}_{2}$ levels were measured using isotope dilution-liquid chromatographytandem mass spectrometry (ID-LC-MS/MS), as described previously. ${ }^{13,14}$ Low, medium and high commercial controls (UTAK Laboratories) were used to monitor assay precision. Sample identity was concealed during testing. As $25(\mathrm{OH}) \mathrm{D}_{2}$ levels were undetectable or negligible in all specimens, we defined $25(\mathrm{OH}) \mathrm{D}_{3}$ levels below $75 \mathrm{nmol} / \mathrm{L}$ as vitamin $\mathrm{D}$ insufficiency, ${ }^{6}$ and below $50 \mathrm{nmol} / \mathrm{L}$ as vitamin D deficiency.

\section{ALRI hospitalisations}

Infant ALRI hospitalisations during the first 12 months of life were identified by International Classification of Diseases, 10th revision, Australian modification (ICD-10AM) codes recorded during admission to Royal Darwin Hospital (J09-J22, A37-A37.9). ${ }^{15}$ Hospital and study data were linked via the Hospital Registration Number, common to each dataset and unique to each infant. Diagnoses made during the birth admission (ICD-10-AM, Z37.0-Z39.2) and related admissions within 7 days of birth were excluded from the analysis.

\section{Analysis}

Vitamin D levels are reported for all available blood samples at each time point. Participant characteristics were assessed according to cord blood vitamin D status categories (<50 nmol/L, 50-74 nmol/L, $\geq 75 \mathrm{nmol} / \mathrm{L}$ ) to assess potential confounders of the exposure. The Fisher exact test (proportional data) and Kruskal-Wallis test (continuous data) were used to assess differences between groups. The primary analysis was a comparison of cord blood $25(\mathrm{OH}) \mathrm{D}_{3}$ levels in infants who were subsequently hospitalised with an ALRI with those of infants who were not. Student $t$ tests were used to compare the normally distributed vitamin D data; $P<0.05$ (two-tailed) was defined as statistically significant. With 84 cord blood samples and assuming that $20 \%$ of infants would be hospitalised with an ALRI ${ }^{1}$ and that mean cord blood $25(\mathrm{OH}) \mathrm{D}_{3}$ levels for healthy infants ranged between 50 and $75 \mathrm{nmol} / \mathrm{L}$ (standard deviation, $25 \mathrm{nmol} / \mathrm{L}$ ), our analysis had $80 \%$ power to detect a difference in $25(\mathrm{OH}) \mathrm{D}_{3}$ levels (between those of infants who were hospitalised for ALRI and of those who were not) of $20 \mathrm{nmol} / \mathrm{L}$.

\section{Ethics approval}

The study was approved by the $\mathrm{Hu}$ man Research Ethics Committee of the NT Department of Health and by the Menzies School of Health Research (HREC 05/52, HREC-20121882). Written consent was obtained for access to each child's medical records and the analysis of their blood samples.

\section{Results}

\section{Participant characteristics}

In general, participant characteristics were similar across the cord blood $25(\mathrm{OH}) \mathrm{D}_{3}$ categories, except that remote dwelling was associated with lower cord blood $25(\mathrm{OH}) \mathrm{D}_{3}$ levels (Box 1). The median maternal age at recruitment was 24 years, and almost half $(43 \%)$ reported smoking during pregnancy. Uptake of the influenza vaccine during pregnancy was low (14\%). Most infants (91\%) had received three doses of the pneumococcal conjugate vaccine (PCV; 7-valent or 10-valent plus Haemophilus influenzae protein D) by 12 months of age.

\section{Vitamin D levels}

As assessed in maternal venous blood, the prevalence of vitamin D insufficiency was $21 \%$ ( 7 of 33 ) during the third trimester (median gestation time, 32 weeks; range, 28-36 weeks) and $45 \%$ (48 of 106) at birth (median gestation time, 39 weeks; range, 34-41 weeks) (Box 2). In cord blood (median gestation time, 39 weeks; range, 36-41 weeks), the prevalence of vitamin $\mathrm{D}$ insufficiency was $80 \%$ (67 of 84 ); $44 \%$ (37 of 84 ) had $25(\mathrm{OH}) \mathrm{D}_{3}$ levels below $50 \mathrm{nmol} / \mathrm{L}$, and $10 \%$ (8 of 84 ) below $25 \mathrm{nmol} / \mathrm{L}$. The prevalence of vitamin D insufficiency among infants at the 7 month visit (median age, 7.1 months; range, $6.6-8.1$ months) was $22 \%$ (8 of 37 ).

Considering all samples (unmatched), the relative difference in mean $25(\mathrm{OH}) \mathrm{D}_{3}$ levels between maternal venous blood during the third trimester and at birth was $23 \%$ (104 nmol/L $v 80 \mathrm{nmol} / \mathrm{L})$ and between maternal venous and cord blood levels at birth $33 \%(80 \mathrm{nmol} / \mathrm{L} \mathrm{v}$ $54 \mathrm{nmol} / \mathrm{L})$ (Box 2; Box 3A). Overall, there was a $48 \%$ relative difference in $25(\mathrm{OH}) \mathrm{D}_{3}$ levels between mothers' levels during the third trimester and those of cord blood. This trend in relative difference was similar in matched samples (data not shown). At birth, the $25(\mathrm{OH}) \mathrm{D}_{3}$ concentrations of the 81 matched maternal venous and cord blood samples exhibited a linear correlation $(r=0.84 ; P<0.001$; Box $3 \mathrm{~B})$.

\section{Vitamin D levels in urban and remote participants}

The mean $25(\mathrm{OH}) \mathrm{D}_{3}$ concentration was lower in remote than in urban participants during pregnancy, at birth, and at infant age 7 months (Box 4). The relative difference in $25(\mathrm{OH}) \mathrm{D}_{3}$ concentration between maternal blood in the third trimester and cord blood in remote participants was $57 \%(87 \mathrm{nmol} / \mathrm{L} v 37 \mathrm{nmol} / \mathrm{L})$, compared with $46 \%$ in urban participants (108 nmol/L $v 58 \mathrm{nmol} / \mathrm{L})$. The cord blood $25(\mathrm{OH}) \mathrm{D}_{3}$ concentrations of all 14 remote infants were below 
1 Participant characteristics, by cord blood $25(\mathrm{OH}) \mathrm{D}_{3}$ status

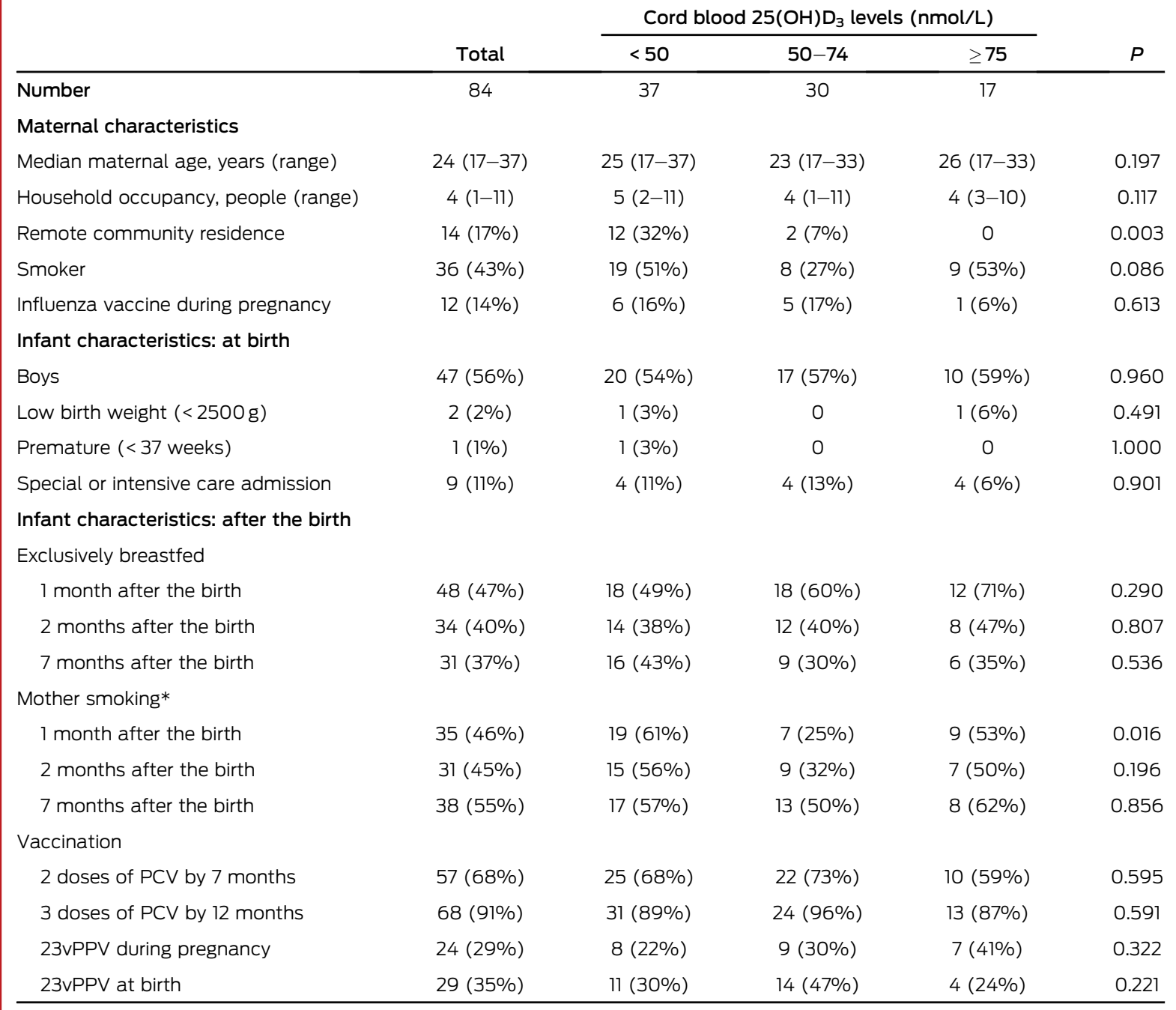

23vPPV = 23-valent pneumococcal polysaccharide vaccine; PCV = pneumococcal conjugate vaccine (the 7-valent pneumococcal conjugate vaccine [7vPCV] or the 10-valent pneumococcal Haemophilus influenzae protein D conjugate vaccine [10vPHID-CV]). All figures are numbers of individuals and column percentages unless otherwise indicated. Data were compared across categories using the Fisher exact test for proportional data and the KruskalWallis test for continuous data. * Smoking data were unavailable for eight mothers at 1 month and for 15 mothers at 2 and 7 months post partum.

$75 \mathrm{nmol} / \mathrm{L} ; 86 \%$ (12 of 14$)$ were under $50 \mathrm{nmol} / \mathrm{L}$ and $14 \%$ (2 of 14$)$ were under $25 \mathrm{nmol} / \mathrm{L}$.

\section{Vitamin D and ALRI hospitalisation}

Of the 84 infants for whom cord blood samples were available, seven (8\%) were hospitalised with an ALRI during their first 12 months of life; the median age at initial admission was 5.3 months (range, $1.9-7.5$ months). In our primary analysis (Box 5), the mean cord blood $25(\mathrm{OH}) \mathrm{D}_{3}$ concentration in these seven infants was $37 \mathrm{nmol} / \mathrm{L}$ (95\% CI, 25-48 nmol/L), compared with $56 \mathrm{nmol} / \mathrm{L}(95 \% \mathrm{CI}$,
51-61 nmol/L) for the 77 infants not hospitalised for an ALRI $(P=0.025)$. Mean $25(\mathrm{OH}) \mathrm{D}_{3}$ levels in maternal venous blood at birth were similarly lower in the mothers of infants subsequently hospitalised with an ALRI than in the mothers of those not hospitalised for an ALRI (Box 5).

\section{ALRI among urban and remote participants}

The proportion of remotely dwelling infants who were hospitalised with an ALRI (4 of 14, 29\%) was higher than for urban infants (3 of 70, $4 \%$; $P=0.013)$. The low number of ALRI hospitalisations was insufficient for a model including remote dwelling as a confounding factor.

\section{Discussion}

This is the first study to longitudinally assess vitamin $D$ levels in pregnant Indigenous mothers and their infants. We found that the mean $25(\mathrm{OH}) \mathrm{D}_{3}$ level in cord blood was about half $(48 \%)$ that of maternal blood during the third trimester of pregnancy (about 7 weeks earlier), a difference due equally to a decline in maternal levels late in pregnancy and to a gradient across the placenta. We also found that the $25(\mathrm{OH}) \mathrm{D}_{3}$ 
2 Serum vitamin $D\left(25(\mathrm{OH}) \mathrm{D}_{3}\right)$ levels measured during pregnancy, at birth, and in the infant at age 7 months

\begin{tabular}{|c|c|c|c|c|c|c|c|c|}
\hline \multirow[b]{2}{*}{ Visit } & \multirow[b]{2}{*}{$\begin{array}{l}\text { Blood } \\
\text { sample }\end{array}$} & \multirow[b]{2}{*}{$n$} & \multirow[b]{2}{*}{$\begin{array}{l}\text { Median age } \\
\text { (range) }\end{array}$} & \multicolumn{5}{|c|}{$25(\mathrm{OH}) \mathrm{D}_{3}$ levels (nmol/L) } \\
\hline & & & & $\begin{array}{c}\text { Mean } \\
(95 \% \mathrm{Cl})\end{array}$ & $\begin{array}{c}\text { Relative } \\
\text { difference* }\end{array}$ & $<50$ & $50-74$ & $\geq 75$ \\
\hline Pregnancy & Maternal & 33 & 32 weeks $^{\dagger}(28-36$ weeks) & $104(93-115)$ & Base & $1(3 \%)$ & $6(18 \%)$ & $26(79 \%)$ \\
\hline Birth & Maternal & 106 & 39 weeks $^{\dagger}$ (34-41 weeks) & $80(74-86)$ & $-23 \%$ & $18(17 \%)$ & $30(28 \%)$ & $58(55 \%)$ \\
\hline Birth & Cord & 84 & 39 weeks $^{\dagger}$ (36-41 weeks) & $54(50-59)$ & $-48 \%$ & $37(44 \%)$ & $30(36 \%)$ & $17(20 \%)$ \\
\hline 7 months & Infant & 37 & 7.1 months $^{\ddagger}$ (6.6-8.1 months) & $93(86-101)$ & $-10 \%$ & $1(3 \%)$ & $7(19 \%)$ & 29 (78\%) \\
\hline
\end{tabular}

concentration was less than $75 \mathrm{nmol} / \mathrm{L}$ in $80 \%$ of cord blood samples, and that the mean cord blood $25(\mathrm{OH}) \mathrm{D}_{3}$ concentration was lower in infants who were subsequently hospitalised with an ALRI than in those who were not $(37 \mathrm{nmol} / \mathrm{L} v 56 \mathrm{nmol} / \mathrm{L}$; $P=0.025)$. This comparison of cord blood vitamin D levels according to ALRI hospitalisation outcome should be interpreted with caution, however, given the small number of ALRI hospitalisations (seven) and an inability to adequately investigate potential confounders, such as remote dwelling. This characteristic was associated with both lower cord blood vitamin D levels and a higher proportion of ALRI hospitalisations, and may have independently caused both low vitamin D levels and increased risk of ALRI hospitalisation. Further, this study did not measure specific factors known to influence vitamin D status, such as skin pigmentation, time spent outdoors, and diet. Despite the limitations of this study, our findings warrant further investigation.

Physiological changes in vitamin D metabolism occur during pregnancy to support the increased calcium demands of the fetus, but the specific mechanisms are not fully understood. Levels of vitamin D-binding protein and the active vitamin $\mathrm{D}$ metabolite, $1,25(\mathrm{OH})_{2} \mathrm{D}$, increase steadily during pregnancy, while concentrations of $25(\mathrm{OH}) \mathrm{D}_{3}$ generally remain stable. ${ }^{16,17}$ In our study, maternal $25(\mathrm{OH}) \mathrm{D}_{3}$ concentrations fell both late in pregnancy (by 23\%) and across the placenta (by 33\%). The observed difference in $25(\mathrm{OH}) \mathrm{D}_{3}$ concentrations between venous (maternal) and cord blood at birth is
3 (A) Maternal and infant vitamin D levels.* (B) Correlation between 84 matched maternal venous and cord blood vitamin $D$ measurements at birth
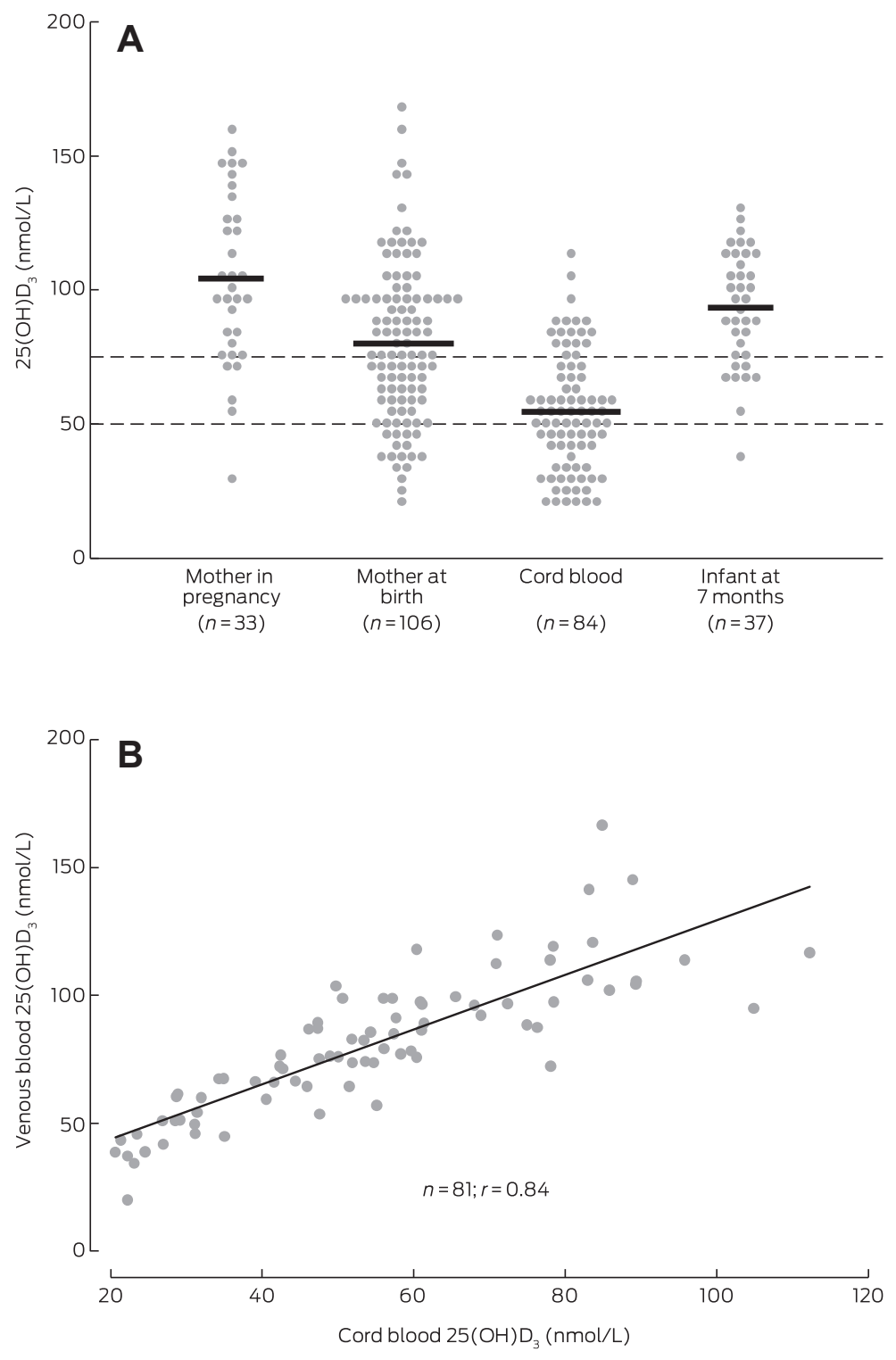

* Dashed lines indicate reference $25(\mathrm{OH}) \mathrm{D}_{3}$ values for vitamin $\mathrm{D}$ deficiency $(<50 \mathrm{nmol} / \mathrm{L})$ and insufficiency $(<75 \mathrm{nmol} / \mathrm{L})$. 
4 Vitamin D levels (nmol/L) for urban and remote dwelling participants

\begin{tabular}{|c|c|c|c|c|c|c|c|c|c|}
\hline \multirow[b]{2}{*}{ Visit } & \multirow[b]{2}{*}{$\begin{array}{l}\text { Blood } \\
\text { sample }\end{array}$} & \multicolumn{4}{|c|}{ Urban } & \multicolumn{4}{|c|}{ Remote } \\
\hline & & $n$ & $\begin{array}{c}\text { Median age } \\
\text { (range) }\end{array}$ & $\begin{array}{l}\text { Mean } 25(\mathrm{OH}) \mathrm{D}_{3} \\
\text { levels }(95 \% \mathrm{Cl})\end{array}$ & $\begin{array}{c}\text { Relative } \\
\text { difference* (\%) }\end{array}$ & $n$ & $\begin{array}{c}\text { Median age } \\
\text { (range) }\end{array}$ & $\begin{array}{l}\text { Mean } 25(\mathrm{OH}) \mathrm{D}_{3} \\
\text { levels }(95 \% \mathrm{Cl})\end{array}$ & $\begin{array}{c}\text { Relative } \\
\text { difference* (\%) }\end{array}$ \\
\hline Pregnancy & Maternal & 26 & 33 weeks $^{\dagger}(30-36)$ & $108(95-122)$ & Base & 7 & 32 weeks $^{\dagger}(28-35)$ & $87(68-107)$ & Base \\
\hline Birth & Maternal & 85 & 39 weeks $^{\dagger}(35-41)$ & $86(79-92)$ & $-23 \%$ & 21 & 39 weeks $^{\dagger}(34-41)$ & $57(49-66)$ & $-34 \%$ \\
\hline Birth & Cord & 70 & 39 weeks $^{\dagger}(36-41)$ & $58(53-63)$ & $-46 \%$ & 14 & 39 weeks $^{\dagger}(37-41)$ & $37(30-43)$ & $-57 \%$ \\
\hline 7 months & Infant & 33 & 7.1 months $^{\ddagger}(6.8-8.1)$ & $94(86-101)$ & $-13 \%$ & 4 & 7.1 months $^{\ddagger}(6.6-8.1)$ & $90(56-124)$ & $+3 \%$ \\
\hline
\end{tabular}

consistent with other studies; ${ }^{18}$ however, few have specifically characterised $25(\mathrm{OH}) \mathrm{D}_{3}$ levels late in pregnancy. In 2003, a small study of 20 Hungarian women found no difference in mean maternal $25(\mathrm{OH}) \mathrm{D}_{3}$ levels between 22-24 weeks' gestation and birth, ${ }^{19}$ while a study of 14 healthy French women found a $20 \%$ decline in mean $25(\mathrm{OH}) \mathrm{D}_{3}$ levels between 36 weeks' gestation $(46.8 \mathrm{nmol} / \mathrm{L})$ and birth $(37.4 \mathrm{nmol} / \mathrm{L}){ }^{20}$ As there is little seasonal variation in $25(\mathrm{OH}) \mathrm{D}_{3}$ levels in the tropical $\mathrm{NT}^{13}$ the drop in late pregnancy may reflect natural progression, perhaps related to maternal-fetal immune tolerance or neonatal immune development, ${ }^{21}$ increased calcium demands of the growing fetus, ${ }^{22}$ or the emergence of risk factors, such as increased body mass index or more time spent indoors. $^{7}$

The cord blood vitamin D data in our study suggest that $80 \%$ of infants were born with vitamin $\mathrm{D}$ insufficiency $(<75 \mathrm{nmol} / \mathrm{L}), 44 \%$ with mild deficiency $(<50 \mathrm{nmol} / \mathrm{L})$, and $10 \%$ with moderate deficiency $(<25 \mathrm{nmol} / \mathrm{L})$. The significance of these definitions for the neonate, however, is unclear, and more work is needed to define vitamin D reference ranges in cord

5 Mean vitamin $D$ levels during pregnancy, at birth, and in the infant at age 7 months, according to infant hospitalisation with an acute lower respiratory infection (ALRI) during the first 12 months of life

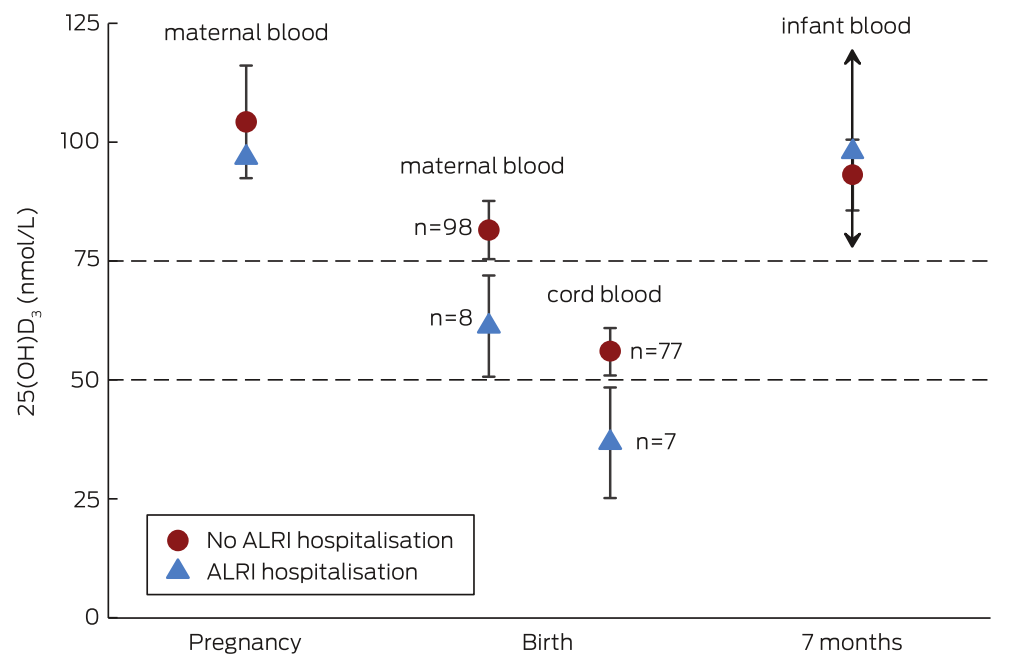

Only one maternal vitamin D measurement during the third trimester of pregnancy was associated with an infant ALRI hospitalisation, so that there is no confidence interval for the open triangle. Only two infants with vitamin D measurements at 7 months were hospitalised with an ALRI, so that the upper and lower confidence boundaries around the open triangle are very wide (exceeding the graph scale), as indicated by the arrows.

blood. Vitamin D status was generally normal by infant age 7 months, the next sampling point.

Concordant with the trends in our data, a recent trial of maternal-plusinfant vitamin $\mathrm{D}$ supplementation for the prevention of deficiency among New Zealand infants 8 showed that mean $25(\mathrm{OH}) \mathrm{D}$ levels in the placebo group were higher in mothers at 36 weeks' gestation $(50 \mathrm{nmol} / \mathrm{L})$ than in cord blood $(33 \mathrm{nmol} / \mathrm{L})$, and that infant levels steadily increased through ages 2 $(50 \mathrm{nmol} / \mathrm{L}), \quad 4 \quad(75 \mathrm{nmol} / \mathrm{L})$ and 6 months $(78 \mathrm{nmol} / \mathrm{L})$. As the authors did not report maternal 25(OH)D levels at birth, it was not possible to determine whether the drop between 36 weeks' gestation and cord blood was the result of a maternal decline or of the placental differential. Compliant daily maternal (from 27 weeks' gestation to birth) and infant supplementation (from birth to age 6 months) at low (1000 and $400 \mathrm{IU} /$ day respectively) and high doses (2000 and $800 \mathrm{IU} /$ day respectively) increased mean cord blood $25(\mathrm{OH}) \mathrm{D}_{3}$ levels to $60 \mathrm{nmol} / \mathrm{L}$ and $65 \mathrm{nmol} / \mathrm{L}$ respectively $(v 33 \mathrm{nmol} / \mathrm{L}$ in placebo-treated participants); mean infant $25(\mathrm{OH}) \mathrm{D}_{3}$ levels of $75 \mathrm{nmol} / \mathrm{L}$ or more were maintained at each of the 2, 4 and 6 months sampling points.

Among the participants who contributed a cord blood sample to our study, there were fewer infant ALRI hospitalisations in the first 12 months of life (8\%) than predicted by historical NT data $(22 \%){ }^{1}$ As ALRI hospitalisation rates are highest among remote and Central Australian infants, ${ }^{1}$ this difference was probably caused by the 
over-representation of Top End and urban infants in our cohort (Top End, $100 \%$; urban, $83 \%$ ) compared with the NT-wide historical data (Top End, $71 \%$, urban, 39\%). Nevertheless, cord blood $25(\mathrm{OH}) \mathrm{D}_{3}$ concentrations were lower in infants who were subsequently hospitalised with an ALRI than in those who were not. We could not reliably adjust our analysis to account for remote dwelling as a confounder because of the low number of ALRI hospitalisations, but our unadjusted findings are consistent with those of several other studies. In the Netherlands, cord blood 25(OH)D concentration was lower in infants who developed a respiratory syncytial virus-associated ALRI during their first 12 months than in controls $(65 \mathrm{nmol} / \mathrm{L} \quad v \quad 84 \mathrm{nmol} / \mathrm{L}$; $P=0.009) ;{ }^{3}$ in New Zealand, lower cord blood $25(\mathrm{OH}) \mathrm{D}$ concentration was associated with an increased risk of any respiratory infection by 3 months of age (odds ratios, 1.00 for $\geq 75 \mathrm{nmol} / \mathrm{L} ; 1.39$ for $25-74 \mathrm{nmol} / \mathrm{L}$; 2.16 for $<25 \mathrm{nmol} / \mathrm{L}){ }^{2}$ In a Korean study, $90 \%$ of 525 cord blood samples tested had 25(OH)D levels below $75 \mathrm{nmol} / \mathrm{L}$, and reduced cord blood $25(\mathrm{OH}) \mathrm{D}$ concentration was strongly associated with increased risk of acute nasopharyngitis during the first 6 months of life. ${ }^{4}$ In their recent randomised controlled trial of vitamin D supplementation, Grant and colleagues ${ }^{23}$ audited health care visits by children (to age 18 months) as a secondary outcome; infants in the high dose group (87\%; 66 of 76 ) but not the low dose supplementation group (95\%; 76 of 80$)$ had significantly fewer health care presentations for acute respiratory infections than infants in the placebo group $(99 \% ; 79$ of 80$)$.

Although not all studies support an inverse association between vitamin $\mathrm{D}$ levels and ALRI risk, a supplementation strategy beginning in the third trimester of pregnancy may be useful in preventing both vitamin D insufficiency and subsequent acute respiratory infections in Indigenous neonates in the NT. Acute respiratory infections are endemic in remote Indigenous communities because of factors such as overcrowding and exposure to tobacco smoke. ${ }^{24}$ However, it is less obvious why remote participants in our study had lower $25(\mathrm{OH}) \mathrm{D}_{3}$ levels during pregnancy and at birth, or why the relative difference in mean concentrations in maternal blood at 30-36 weeks' gestation and in cord blood was greater than in their urban counterparts (remote, $-57 \%$ v urban, $-48 \%$ ). Similar vitamin D levels in urban and remote infants at age 7 months suggest that the negative influence of remoteness on vitamin $\mathrm{D}$ levels was confined to the mothers. As the climate and time spent outdoors are likely to be similar for urban and remote participants, risk factors other than exposure to sunlight require further investigation. Interestingly, vitamin D has also been found to be a negative acute phase reactant that is depleted after an inflammatory insult. ${ }^{25}$ Lower vitamin D levels seen among remote participants may therefore be the result, rather than a cause, of their high burden of infection.

\section{Conclusions}

While only one in five Indigenous mothers had $25(\mathrm{OH}) \mathrm{D}_{3}$ levels below $75 \mathrm{nmol} / \mathrm{L}$ midway through the third trimester of their pregnancy, four in five cord bloods tested had lower levels as the result of declining $25(\mathrm{OH}) \mathrm{D}_{3}$ levels late in pregnancy and differences in levels across the placenta. The significance of low cord blood $25(\mathrm{OH}) \mathrm{D}_{3}$ concentrations is unclear, but the seven infants hospitalised with an ALRI during their first 12 months of life had significantly lower levels than those not hospitalised with an ALRI. Our findings, in conjunction with emerging international data, support the need for further longitudinal studies and for randomised controlled trials of vitamin D supplementation for the prevention of infant ALRI.

Acknowledgements: We thank all the children families and carers who participated in these studies, and acknowledge funding support from the National Health and Medical Research Council (APP1017225), the Australian Academy of Science, the Channel 7 Children's Research Foundation (12517), and the Menzies School of Health Research.

Competing interests: No relevant disclosures. Received 13 July 2015, accepted 10 Dec 2015. C 2016 AMPCo Pty Ltd. Produced with Elsevier B.V. All rights reserved. 
1 O'Grady KA, Torzillo PJ, Chang AB. Hospitalisation of Indigenous children in the Northern Territory for lower respiratory illness in the first year of life. Med J Aust 2010; 192: 586-590. https://www.mja.com.au/journal/ 2010/192/10/hospitalisationindigenous-children-northern-territorylower-respiratory-illness

2 Camargo CA, Ingham T, Wickens K, et al. Cord-blood 25-hydroxyvitamin D levels and risk of respiratory infection, wheezing, and asthma. Pediatrics 2011; 127: el80-el87.

3 Belderbos ME, Houben ML, Wilbrink B, et al. Cord blood vitamin D deficiency is associated with respiratory syncytial virus bronchiolitis. Pediatrics 2011; 126: el513-el520.

4 Shin $\mathrm{YH}, \mathrm{YU}$ J, Kim KW, et al. Association between cord blood 25hydroxyvitamin $\mathrm{D}$ concentrations and respiratory tract infections in the first 6 months of age in a Korean population: a birth cohort study (COCOA). Korean J Pediatr 2013; 56 : 439-445.

5 Mora JR, Iwata M, von Andrian UH. Vitamin effects on the immune system: vitamins $A$ and $D$ take centre stage. Nat Rev Immunol 2008; 8 : 685-698.

6 Holick MF, Binkley NC, Bischoff-Ferrari HA, et al. Evaluation, treatment, and prevention of vitamin $D$ deficiency: an Endocrine Society clinical practice guideline. J Clin Endocrinol Metab 2011; 96: 1911-1930.

7 Paxton GA, Teale GR, Nowson CA, et al. Vitamin $D$ and health in pregnancy, infants, children and adolescents in Australia and New Zealand: a position statement. Med J Aust 2013; 198: 142-143. https://www.mja.com.au/ journal/2013/198/3/vitamin-d-andhealth-pregnancy-infants-childrenand-adolescents-australia-and-new

8 Grant CC, Stewart AW, Scragg R, et al. Vitamin $D$ during pregnancy and infancy and infant serum 25hydroxyvitamin $\mathrm{D}$ concentration. Pediatrics 2014; 133: el43-el53.

9 Grant CC, Wall CR, Crengle S, Scragg R. Vitamin $D$ deficiency in early childhood: prevalent in the sunny South Pacific. Public Health Nutr 2009; 12: 1893-1901.

10 McLeod DS, Scott KA, Lust KM, McIntyre HD. Routine screening for vitamin $\mathrm{D}$ deficiency in early pregnancy [letter]. Med J Aust 2011; 195: 384-385. https://www.mja.com. au/journal/2011/195/7/routinescreening-vitamin-d-deficiency-earlypregnancy

1 Grover SR, Morley R. Vitamin D deficiency in veiled or dark-skinned pregnant women. Med J Aust 2001; 175: 251-252. https://www.mja.com.au/ journal/2001/175/5/vitamin-ddeficiency-veiled-or-dark-skinnedpregnant-women

12 Bendall A, de Costa C, Woods C, Howat P. Vitamin $D$ levels in pregnant women booking for antenatal care in Far North Queensland. Aust N Z J Obstet Gynaecol 2012; 52: 391-394.

13 Binks MJ, Smith-Vaughan HC, Bar-Zeev N, et al. Vitamin D insufficiency among hospitalised children in the Northern Territory. J Paediatr Child Health 2014; 50: 512-518.

14 Maunsell Z, Wright DJ, Rainbow SJ. Routine isotope-dilution liquid chromatography-tandem mass spectrometry assay for simultaneous measurement of the 25-hydroxy metabolites of vitamins D2 and D3. Clin Chem 2005; 51: 1683-1690.

15 National Centre for Classification in Health. The International Statistical Classification of Diseases and Related Health Problems, 10th Revision, Australian modification (ICD-10-AM), 6th edition. Sydney: National Centre for Classification in Health, Faculty of Health Sciences, The University of Sydney, 2009.
16 Brannon PM, Picciano MF. Vitamin D in pregnancy and lactation in humans. Annu Rev Nutr 2011; 31: 89-115.

17 Papapetrou PD. The interrelationship of serum 1,25-dihydroxyvitamin D, 25-hydroxyvitamin D and 24,25dihydroxyvitamin $\mathrm{D}$ in pregnancy at term: a meta-analysis. Hormones 2010; 9: 136-144.

18 Waiters B, Godel JC, Basu TK. Perinatal vitamin $D$ and calcium status of northern Canadian mothers and their newborn infants. J Am Coll Nutr 1999; 18: 122-126.

19 More C, Bhattoa HP, Bettembuk P, Balogh A. The effects of pregnancy and lactation on hormonal status and biochemical markers of bone turnover. Eur J Obstet Gynecol Reprod Biol 2003; 106: 209-213.

20 Salle BL, Delvin EE, Lapillonne A, et al. Perinatal metabolism of vitamin D. Am J Clin Nutr 2000; 71 (5 Suppl): 1317S-1324S.

21 Tamblyn JA, Hewison M, Wagner CL, et al. Immunological role of vitamin D at the maternal-fetal interface. $J$ Endocrinol 2015; 224: R107-R121.

22 Kovacs CS. Vitamin D in pregnancy and lactation: maternal, fetal, and neonatal outcomes from human and animal studies. Am J Clin Nutr 2008; 88: 520S-528S.

23 Grant CC, Kaur S, Waymouth E, et al. Reduced primary care respiratory infection visits following pregnancy and infancy vitamin D supplementation: a randomised controlled trial. Acta Paediatr 2015; 104: 396-404.

24 O'Grady KA, Chang AB. Lower respiratory infections in Australian Indigenous children. J Paediatr Child Health 2010; 46: 461-465.

25 Gama R, Waldron JL, Ashby HL, et al. Hypovitaminosis D and disease: consequence rather than cause? BMJ 2012; 345: e5706. 